\title{
QUALIDADE SANITÁRIA DE GRÃOS DE MILHO COM E SEM INOCULAÇÃO A CAMPO DOS FUNGOS CAUSADORES DE PODRIDÕES DE ESPIGA
}

\author{
Sanitary quality of corn grains with and without in-field inoculation \\ with corn ear rot causing fungi \\ Marcelo Cruz Mendes ${ }^{1}$, Renzo Garcia Von Pinho², José da Cruz Machado², \\ Carlos Juliano Brant Albuquerque ${ }^{3}$, Júlio Cesar Fabro Falquete ${ }^{2}$
}

\begin{abstract}
RESUMO
O uso sucessivo de híbridos de milho com resistência variada aos fungos causadores de podridão de grãos tem causado aumento na importância dessas doenças a cada safra. Conduziu-se este trabalho com o objetivo de avaliar pelo teste de sanidade (blotter test) a severidade do fungo Fusarium verticilioides e a incidência dos fungos Stenocarpella maydis e Stenocarpella macrospora em grãos de milho, oriundos de híbridos comerciais, com e sem a inoculação artificial a campo, em dois sistemas de cultivo, convencional e sistema de semeadura direta e em dois anos agrícolas. O experimento foi conduzido a campo, em blocos casualizados, com três repetições. Em laboratório, foram avaliadas, pelo método de "blotter test", a severidade do fungo F. verticilioides e a incidência dos fungos S. maydis e S. macrospora causadores de podridões de espiga. A avaliação pelo teste de sanidade (blotter test) evidenciou a diferença entre os híbridos quanto a reação aos fungos F.verticilioides, S. maydis e S. macrospora. Houve influência do híbrido, da safra agrícola e do sistema de cultivo sobre a infecção dos fungos causadores de podridões de espigas, sendo que o sistema plantio direto favorece o aumento dos fungos responsáveis pelos grãos ardidos em milho. A utilização da inoculação artificial, em campo, visando a selecionar genótipos resistentes aos fungos causadores do "complexo de grãos ardidos" é eficiente.
\end{abstract}

Termos para indexação: Grãos ardidos, Zea mays, blotter test, Fusarium verticilioides, Stenocarpella spp.

\begin{abstract}
The continued use of corn hybrids with varied resistance to grain rot-causing fungal agents increases the importance of these diseases every year. The objective of this work was to evaluate, by a sanitary test (blotter test), the severity of the fungus Fusarium verticilioides and the incidence of Stenocarpella maydis and Stenocarpella macrospora in corn grain from commercial hybrids, with and without in-field artificial inoculation, under two cultivation systems (conventional and direct sowing), over two crop seasons. The experiment was carried out under field conditions, using an experimental randomized blocks design, with three replications. In the laboratory, the severity of $F$. verticilioides and the incidence of S. maydis and S. macrospora, the causative agents of ear rot in corn, were evaluated by the "blotter test" method. The blotter test evaluation allowed us to detect differences between the hybrids in their reactions to the fungi $F$. verticilioides, $S$. maydis and $S$. macrospora. The crop season and cultivation system used had the most influence on fungal infection in the hybrids. The direct sowing system showed an increase in the fungal infection responsible for causing grain rot. The use of artificial inoculation, in-field, to select genotypes resistant to the fungal agents causing the "grain rot complex" is efficient.
\end{abstract}

Index terms: Grain rot, Zea mays, artificial inoculation, Fusarium verticilioides, Stenocarpella spp.

(Recebido em 21 de julho de 2009 e aprovado em 6 de abril de 2010)

\section{INTRODUÇÃO}

Os grãos ardidos em milho são consequências das podridões de espigas causadas, principalmente, pelos fungos presentes no campo, como o Fusarium verticilioides, Stenocarpella maydis e S. macrospora. Muitas dessas espécies, além de causar danos físicos (descoloração dos grãos, redução nos conteúdos de carboidratos, de proteínas e de açúcares totais), causam perdas qualitativas, pela produção de compostos tóxicos, chamados de micotoxinas, sendo uma ameaça à saúde animal e humana (PINTO, 2001).

Ao longo dos últimos anos tem se observado um avanço das doenças nessa cultura, como consequência do estreitamento das relações patógeno-hospedeiroambiente (COSTA, 2001). Aparentemente, o aumento na incidência e severidade das doenças pode ser explicado por vários dos fatores que contribuíram para o crescimento da produção (aumento de área, população de plantas, manejo de doenças e disponibilidade hídrica) e também

'Universidade Estadual do Centro-Oeste do Paraná/UNICENTRO - Departamento de Agronomia - Rua Simeão Varela de Sá - Cascavel - $85040-080$ Guarapuava, PR - mcmendes@unicentro.br

2Universidade Federal de Lavras/UFLA - Lavras, MG

${ }^{3}$ Empresa de Pesquisa Agropecuária de Minas Gerais/EPAMIG - Nova Porterinha, MG 
pelo deslocamento da cultura para novas regiões (OLIVEIRA et al., 2005).

O controle das podridões de grãos envolve ações integradas, dentre elas destacam-se o manejo dos restos culturais, a rotação de culturas e a utilização de cultivarem resistentes. Porém, cada vez mais tem se tornado uma prática comum, a utilização por parte de alguns agricultores, de híbridos com resistência variada, aos fungos causadores de podridão de grãos, fazendo com que a importância dessas doenças aumente a cada safra (CASA et al., 2006).

Para a identificação de híbridos de milho resistentes ao complexo de fungos, causadores de grãos ardidos em milho, as empresas produtoras de sementes têm utilizado muito a inoculação artificial (KLAPPROTH; HAWK, 1991; BENSCHet al., 1992). Por outro lado, é de suma importância a diagnose e a identificação, em laboratório, dos fungos que estão incidindo sobre os grãos. O teste de sanidade (método de blotter test) é uma alternativa prática e viável para essa finalidade. Este teste permite, além de uma melhor avaliação da tolerância dos materiais aos fungos causadores de podridões de espigas, estudar a reação a cada espécie de fungo separadamente (MARIO; REIS, 2001).

Neste trabalho, objetivou-se avaliar pelo teste de sanidade (blotter test) a severidade do fungo Fusarium verticilioides e a incidência dos fungos Stenocarpella maydis e Stenocarpella macrospora em grãos de milho, oriundos de híbridos comerciais, com e sem a inoculação artificial a campo, em dois sistemas de cultivo, convencional e sistema de semeadura direta e em dois anos agrícolas.

\section{MATERIAL E MÉTODOS}

Os experimentos foram conduzidos em dois locais, nas safras agrícolas de 2006/07 e 2007/08. Em Lavras, MG, dois experimentos (um em cada safra) foram conduzidos em área experimental do Departamento de Agricultura (DAG) da Universidade Federal de Lavras (UFLA). A

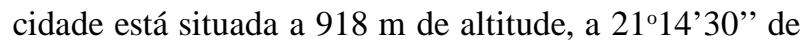
latitude sul e 4500'10'" de longitude oeste. Nesse local, a instalação dos experimentos foi no sistema de plantio convencional, numa área onde é comum o plantio de milho após milho, sem rotação de culturas. Outros dois experimentos foram instalados na Fazenda Palheta, em área pertencente ao Aviário Santo Antônio-ASA, no município de Luminárias, MG. Esse local está situado a 1000 m de altitude, sendo a $21^{\circ} 51^{\prime} 00^{\prime \prime}$ de latitude sul e 44⒐'00" de longitude oeste. Nesta segunda área, os experimentos foram instalados em sistema de plantio direto, adotando como cultura de inverno, o nabo forrageiro e/ou tremoço, em sucessão ao milho. Segundo a classificação de Köppen, o clima em ambas as áreas é considerado como mesotérmico, apresentando verões brandos e chuvosos (Cwb).

Os experimentos foram instalados na primeira quinzena do mês de novembro e as colheitas ocorreram na primeira quinzena de maio, após a maturidade fisiológica. Foram utilizados dez híbridos de milho, sendo divididos em dois grupos, de acordo com a sua reação aos fungos Fusarium verticilioides, Stenocarpella maydis $e$ Stenocarpella macrospora baseado em dados fornecidos pelas empresas produtoras de sementes. O grupo 1 foi composto por híbridos resistentes (AG 6018, AG 8021, DKB 199, 2 A 525 e NB 7215) e o grupo 2 por híbridos suscetíveis a esses fungos (DKB 350, DKB 390, P30F53, 2 B 710 e NB 7210). O delineamento experimental foi o de blocos casualizados com três repetições, em esquema fatorial 10x4, sendo dez híbridos de milho e quatro tratamentos de inoculação de fungos patogênicos, sendo três com inoculação artificial dos fungos Fusarium verticilioides, Stenocarpella maydis e Stenocarpella macrospora e um tratamento testemunha, sem inoculação.

Para proceder à inoculação artificial, foram cedidas pela empresa Monsanto do Brasil S.A., amostras de grãos de milho inoculadas com os fungos $F$. verticilioides, $S$. maydis e $S$. macrospora, oriundas dos municípios de Uberlândia, MG, Chapadão do Sul, MS e Iraí de Minas, MG, respectivamente. As amostras de grãos de milho inoculados foram colocadas em meio de $B D A$ (batatadextrose-agar) por um período de três a cinco dias para que esses fungos pudessem ser isolados. Após a formação das colônias, discos contendo micélio foram transferidos para um substrato com a finalidade de produzir esporos.

A suspensão de conídios utilizada nos trabalhos de inoculação foi ajustada por meio de contagem em câmara de Neubauer para $4 \times 10^{4}$ conídios $\mathrm{ml}^{-1}$. As inoculações foram feitas nas duas linhas componentes de cada parcela, sempre no final do dia, quando a temperatura se encontrava amena. Para $S$. maydis e $S$. macrospora, o método de inoculação artificial foi o de deposição e para o fungo $F$. verticilioides o método de inoculação foi o de aspersão.

Para os fungos $S$. maydis e $S$. macrospora foram depositados $5 \mathrm{~mL}$ de uma suspensão com 4 x $10^{4}$ conídios $\mathrm{ml}^{-1}$, na bainha da folha onde se insere a espiga, dez dias após todas as plantas da parcela terem emitido o estiloestigma (BENSCH et al., 1992). Nesse mesmo estádio da cultura, foram aspergidos nos estilo-estigmas de cada espiga, $5 \mathrm{~mL}$ de uma suspensão com 4 x $10^{4}$ conídios $\mathrm{mL}^{-1}$ de F. verticilioides (MARIO; REIS, 2001).

As espigas provenientes de cada um dos experimentos foram debulhadas e os grãos homogeneizados, previamente à coleta das amostras compostas, oriunda das 
três repetições a campo para cada híbrido, respeitando os tratamentos realizados a campo. No laboratório de Patologia de Sementes, do Departamento de Fitopatologia da Universidade Federal de Lavras, foram montados dois novos experimentos, pelo teste de sanidade "blotter test". O primeiro, visando a avaliar a severidade do fungo $F$. verticilioides e o segundo a incidência de $S$. maydis e $S$. macrospora. $\mathrm{O}$ delineamento utilizado foi o inteiramente casualizado, em arranjo fatorial $10 \times 2$, correspondente aos dez híbridos e os dois tratamentos (no primeiro experimento - inoculado com o fungo $F$. verticilioides e o tratamento testemunha e, no segundo experimento - inoculado com o fungo $S$. maydis e com $S$. macrospora). O tratamento testemunha foi conduzido até o $15^{\circ}$ dia para análise de incidência de $S$. maydis e $S$. macrospora. De cada amostra composta foram retirados 100 grãos, os quais foram dispostos em quatro placas de petri, para realização do teste de sanidade (blotter test). Para se determinar a severidade de infecção por semente, utilizou- se uma adaptação da metodologia proposta por McKinney (1923).

Inicialmente, realizou-se a análise de variância individual e, posteriormente, a análise conjunta envolvendo os dois anos agrícolas para cada sistema de cultivo. Quando necessário, os dados obtidos foram transformados em $\log \mathrm{x}$ e as médias submetidas ao teste de Scott Knott, por meio do programa estatístico SISVAR (FERREIRA, 2002).

\section{RESULTADOS E DISCUSSÃO}

Inicialmente, é importante ressaltar que a precipitação pluviométrica ocorrida durante a condução dos experimentos ultrapassou os $600 \mathrm{~mm}$, nas duas safras e nos dois locais. Esse valor é considerado suficiente para a obtenção de boas produções de grãos de milho, apesar da distribuição das chuvas não ter sido muito uniforme. Vale ressaltar que, nesse período, as temperaturas médias sempre estiveram acima de $20^{\circ} \mathrm{C}$, valor acima do mínimo necessário para o bom desenvolvimento da planta de milho. Assim, pode-se afirmar que as condições climáticas ocorridas durante a condução dos experimentos foram consideradas normais para o bom desenvolvimento da cultura.

Quando analisadas as precipitações ocorridas no sistema convencional de cultivo, constatou-se, na primeira safra (2006/07), uma grande precipitação no mês de janeiro, ultrapassando os $550 \mathrm{~mm}$ de chuva. Vale ressaltar que nesse mês foram feitas as inoculações dos fungos $F$. verticilioides, $S$. maydis e S. macrospora. Na fase de enchimento de grãos e final de ciclo da cultura, houve uma redução na precipitação. Esse fato não ocorreu na segunda safra (2007/08), onde houve distribuição mais uniforme das chuvas e, consequentemente, maior volume de chuvas no final do ciclo da cultura. Esse aumento no volume de chuvas no período de enchimento de grãos e no final de ciclo das plantas, pode acarretar em maiores valores de severidade e incidência dos fungos relacionados ao "complexo de grãos ardidos" (EMBRAPA, 2006; FANCELLI; DOURADO NETO, 2000). O resumo da análise de variância conjunta envolvendo os dois anos (safras) em sistema de plantio convencional, estão apresentados na Tabela 1.

Para a severidade do $F$. verticilioides houve significância $(\mathrm{P} \leq 0,01)$ para híbridos, safras, inoculações e para a interação híbridos x safras, híbridos x inoculações e para a interação tripla híbridos x safras x inoculações. Para a incidência de $S$. maydis e $S$. macrospora, houve significância $(\mathrm{P} \leq 0,01)$ para todas as fontes de variações, com exceção de safras.

Na primeira safra (2006/07), os valores obtidos pela avaliação da severidade, pelo teste de sanidade (blotter test), foram maiores nos tratamentos inoculados artificialmente com o fungo $F$. verticilioides, comparado ao tratamento testemunha (sem inoculação) (Tabela 2). Os híbridos AG 6018 e AG 8021 apresentaram os menores valores de severidade no tratamento inoculado artificialmente, evidenciando uma maior resistência ao fungo $F$. verticilioides. É importante enfatizar que esses híbridos estão no grupo considerado resistente, pelas empresas produtoras de sementes, aos fungos causadores de podridões de espigas (Tabela 2).

Os híbridos DKB 350, DKB 390 e NB 7210, pertencentes ao grupo considerado susceptível à podridão de grãos, apresentaram os maiores valores de severidade, quando inoculados com o fungo $F$. verticilioides. A média da severidade do tratamento inoculado com $F$. verticilioides foi de $41,02 \%$, sendo superior à média obtida para o tratamento testemunha (sem inoculação) que foi de $32,10 \%$. Esse fato, pode comprovar o efeito das inoculações, mesmo em condições adversas ao desencadeamento das podridões de espiga.

O hibrido 2 A 525 apresentou os menores valores de severidade na segunda safra (2007/08), quando submetido à inoculação artificial ( $F$. verticilioides), e enquadrou-se no grupo de híbridos que obteve os menores valores para a infecção natural, tratamento testemunha (sem inoculação), compostos dos híbridos AG 6018 e AG 8021, não diferindo estatisticamente (Tabela 2). Esse resultado, comprova os dados repassados pela empresas produtoras de sementes, visto que esse híbrido é considerado resistentes aos fungos causadores de grãos ardidos. 
Tabela 1 - Resumo da análise de variância conjunta envolvendo as duas safras agrícolas (2006/07 e 2007/08) em sistema convencional, para as avaliações de severidade de $F$. verticilioides e incidência de $S$. maydis e S. macrospora. UFLA, Lavras-MG, 2008.

\begin{tabular}{|c|c|c|c|}
\hline \multirow[b]{2}{*}{ Fonte de variação } & \multirow[b]{2}{*}{ GL } & \multicolumn{2}{|c|}{ QM } \\
\hline & & $\begin{array}{c}\text { Severidade } \\
F . \text { verticilioides }\end{array}$ & $\begin{array}{c}\text { Incidência } \\
\text { S. maydis e S. macrospora }\end{array}$ \\
\hline Bloco (Safra) & 6 & 12,47 & 24,10 \\
\hline Híbridos $(\mathrm{H})$ & 9 & $89,29^{* *}$ & $456,10^{* *}$ \\
\hline Inoculações (I) & 1 & $640,00^{* *}$ & $4796,10^{* *}$ \\
\hline Safra $(\mathrm{S})$ & 1 & $6330,25^{* *}$ & $8,10^{\mathrm{NS}}$ \\
\hline $\mathrm{H}^{*} \mathrm{I}$ & 9 & $64,04^{*}$ & $370,76^{* *}$ \\
\hline $\mathrm{H}^{*} \mathrm{~S}$ & 9 & $73,30^{* *}$ & $223,65^{* *}$ \\
\hline$I^{*} \mathrm{~S}$ & 1 & $33,85^{\mathrm{NS}}$ & $1232,10^{* *}$ \\
\hline $\mathrm{H}^{*} \mathrm{I}^{*} \mathrm{~S}$ & 9 & $126,98^{* *}$ & $204,54^{* *}$ \\
\hline Erro & 114 & 18,98 & 27,67 \\
\hline $\mathrm{CV}(\%)$ & & 10,17 & 40,55 \\
\hline Média Geral & & 42,85 & 12,97 \\
\hline
\end{tabular}

${ }^{* *} \mathrm{P} \leq 0,01 ;{ }^{\text {NS }}$ Não significativo.

Tabela 2 - Médias de severidade (\%) do fungo Fusarium verticilioides (F) frente ao tratamento testemunha (T), sem inoculação, considerando dez híbridos de milho em sistema convencional, analisados nas safras agrícolas de 2006/07 e 2007/08. UFLA, Lavras, MG, 2008.

\begin{tabular}{ccccc}
\hline & \multicolumn{2}{c}{ SAFRA 2006/07 } & F & T \\
\hline Híbrido & $\mathrm{F}$ & $\mathrm{T}$ & $46,60 \mathrm{bA}$ & $44,00 \mathrm{aA}$ \\
AG 6018 & $33,20 \mathrm{aB}$ & $26,00 \mathrm{aA}$ & $49,40 \mathrm{bA}$ & $45,20 \mathrm{aA}$ \\
AG 8021 & $32,00 \mathrm{aA}$ & $29,20 \mathrm{aA}$ & $46,40 \mathrm{bA}$ & $38,00 \mathrm{bA}$ \\
DKB 199 & $38,60 \mathrm{bB}$ & $28,00 \mathrm{aA}$ & $41,80 \mathrm{aA}$ & $41,60 \mathrm{aA}$ \\
2 A 525 & $40,00 \mathrm{bB}$ & $30,60 \mathrm{aA}$ & $51,60 \mathrm{cA}$ & $49,00 \mathrm{bA}$ \\
NB 7215 & $42,80 \mathrm{bB}$ & $32,80 \mathrm{aA}$ & $57,60 \mathrm{cB}$ & $50,80 \mathrm{bA}$ \\
DKB 350 & $46,60 \mathrm{cB}$ & $36,40 \mathrm{bA}$ & $49,80 \mathrm{bA}$ & $50,60 \mathrm{bA}$ \\
DKB 390 & $47,20 \mathrm{cA}$ & $35,60 \mathrm{bA}$ & $49,40 \mathrm{bA}$ & $51,80 \mathrm{bA}$ \\
P 30F53 & $40,80 \mathrm{bB}$ & $31,60 \mathrm{aA}$ & $52,00 \mathrm{cA}$ & $47,80 \mathrm{bA}$ \\
2 B 710 & $43,20 \mathrm{bB}$ & $38,40 \mathrm{bA}$ & $54,20 \mathrm{Cb}$ & $47,20 \mathrm{bA}$ \\
NB 7210 & $45,80 \mathrm{cB}$ & $32,40 \mathrm{aA}$ & 49,88 & 46,60 \\
\hline MEDIA & 41,02 & 32,10 &
\end{tabular}

${ }^{1}$ Médias seguidas de mesma letra minúsculas na coluna não diferem entre si pelo teste de Scott Knott, em nível de significância de 5\%; médias seguidas de mesma letra maiúscula na linha, dentro de cada safra, não diferem significativamente pelo teste $\mathrm{F}$, em nível de significância de 5\%.

De maneira geral, os valores médios de severidade do fungo F.verticilioides foram maiores na segunda safra (2007/08), para ambos os tratamentos, inoculados e sem inoculação (Tabela 3). Esses valores já eram esperados, pois na segunda safra (2007/08) houve maior índice de pluviosidade na fase final do ciclo da cultura.

Os altos valores de severidade obtidos, mesmo no tratamento testemunha (sem inoculação), alertam para os cuidados que devem ser tomados quanto à utilização desses 
grãos na alimentação de animais, ou mesmo para seres humanos. Principalmente, em decorrência de possíveis contaminações por micotoxinas, produzidas pelo fungo F.verticilioides.

É importante enfatizar que, os híbridos considerados susceptíveis ao complexo "grãos ardidos" foram os que obtiveram os maiores valores para a severidade do fungo F.verticilioides. Outro fato importante é que a severidade dos tratamentos inoculados foi superior ao tratamento testemunha (sem inoculação), evidenciando, mais uma vez, o efeito das inoculações artificiais a campo. $\mathrm{O}$ fato de ter havido a presença do fungo $F$. verticilioides, nas parcelas não inoculadas, pode ser explicado com base nas características do fungo, que apresenta elevada esporulação e taxa de dispersão atmosférica.

Embora trabalhos semelhantes conduzidos em condições de campo por Mario e Reis (2003) tenham encontrado $S$. macrospora, em tratamentos foi feito inoculação artificial da $S$. maydis, o mesmo não ocorreu nesta pesquisa. Vale salientar também que, na avaliação pelo teste de sanidade (blotter test) no tratamento testemunha (sem inoculação), não foi constatada a incidência dos fungos $S$. maydis e $S$. macrospora, mesmo após 20 dias de encubação.

Na primeira safra (2006/07), os híbridos considerados susceptíveis obtiveram valores de incidência de $S$. maydis superiores a média $22,00 \%$, sendo o hibrido
DKB 390, considerado susceptível, o que apresentou a maior incidência, 59,00\% (Tabela 3). Esses valores são considerados suficientes para permitir diferenciar níveis de resistência. Segundo Flett e McLaren (1994), é necessário uma incidência mínima de $17 \%$, para que sejam detectadas diferenças quanto à reação de híbridos a Stenocarpella spp.

Houve diferença significativa para os valores da incidência de $S$. maydis nos híbridos avaliados na segunda safra (2007/08). Os valores de incidência de $S$. maydis, obtidos pelos híbridos considerados resistentes, ficaram abaixo da média observada $(10,30 \%)$, diferindo estatisticamente dos valores obtidos para os híbridos considerados susceptíveis, que obtiveram incidências acima da média observada (Tabela 3). Esses dados confirmam os resultados repassados pelas empresas produtoras de sementes quanto à tolerância dos híbridos aos fungos causadores do "complexo grãos ardidos".

Não houve diferença significativa entre os híbridos para a incidência de $S$. macrospora na primeira safra (2006/07), sendo que a incidência de $S$. macrospora foi, em média, cinco vezes inferior a de $S$. maydis (Tabela $3)$. Esses dados diferem dos obtidos por Mario e Reis (2003), em experimentos conduzidos em plantio direto, no Estado do Rio Grande do Sul, onde após inoculação artificial dos fungos $S$. maydis e S. macrospora, obteve

Tabela 3 - Médias de incidência (\%) dos fungos Stenocarpella maydis (MY) e Stenocarpella macrospora (MA) em dez híbridos de milho em sistema convencional de cultivo, analisado nas safras agrícolas de 2006/07 e 2007/08. UFLA, Lavras, MG, $2008 .{ }^{1}$

\begin{tabular}{ccccc}
\hline \multicolumn{3}{c}{ MY } & $2006 / 07$ & MA \\
\hline Híbrido & $2006 / 07$ & $2007 / 08$ & $7,00 \mathrm{aB}$ & $11,00 \mathrm{aA}$ \\
\hline AG 6018 & $10,00 \mathrm{aA}$ & $12,00 \mathrm{aA}$ & $4,00 \mathrm{aA}$ & $9,00 \mathrm{aA}$ \\
AG 8021 & $12,00 \mathrm{bA}$ & $9,00 \mathrm{aA}$ & $4,00 \mathrm{aA}$ & $4,00 \mathrm{aA}$ \\
DKB 199 & $15,00 \mathrm{bA}$ & $6,00 \mathrm{aB}$ & $4,00 \mathrm{aA}$ & $7,00 \mathrm{aA}$ \\
2 A 525 & $16,00 \mathrm{bA}$ & $10,00 \mathrm{aA}$ & $4,00 \mathrm{aA}$ & $9,00 \mathrm{aA}$ \\
NB 7215 & $6,00 \mathrm{aA}$ & $12,00 \mathrm{aA}$ & $3,00 \mathrm{aA}$ & $9,00 \mathrm{aA}$ \\
DKB 350 & $16,00 \mathrm{bA}$ & $18,00 \mathrm{bA}$ & $6,00 \mathrm{aA}$ & $15,00 \mathrm{bA}$ \\
DKB 390 & $59,00 \mathrm{dA}$ & $24,00 \mathrm{bB}$ & $5,00 \mathrm{aA}$ & $11,00 \mathrm{aA}$ \\
P 30F53 & $27,00 \mathrm{bB}$ & $24,00 \mathrm{bA}$ & $4,00 \mathrm{aA}$ & $15,00 \mathrm{bA}$ \\
2 B 710 & $36,00 \mathrm{cA}$ & $21,00 \mathrm{bB}$ & $4,00 \mathrm{aA}$ & $13,00 \mathrm{bA}$ \\
NB 7210 & $25,00 \mathrm{bA}$ & $19,00 \mathrm{bA}$ & 4,50 & 10,30 \\
\hline MEDIA & 22,20 & 15,50 &
\end{tabular}

${ }^{1}$ Médias seguidas de mesma letra minúsculas na coluna não diferem entre si pelo teste de Scott Knott, em nível de significância de 5\%; médias seguidas de mesma letra maiúscula na linha, dentro de cada safra, não diferem significativamente pelo teste $\mathrm{F}$, em nível de significância de $5 \%$. 
valores de incidência de $S$. macrospora quatro vezes superior. Na segunda safra (2007/08), houve diferença entre os híbridos para a incidência de $S$. macrospora, sendo os híbridos que obtiveram a maior incidência o DKB 390, 2 B 710 e NB 7210, com os seguintes valores $15,0,15,0$ e 13,0\% de incidência. Porém, esses valores podem ser considerados insuficientes para permitir diferenciar níveis de resistência, por estarem abaixo de $17 \%$ de incidência (Tabela 3).

Com base nas precipitações ocorridas no sistema de plantio direto, pode-se constatar que na primeira safra (2006/07), houve uma grande precipitação no mês de janeiro, ultrapassando os $650 \mathrm{~mm}$ de chuva, coincidindo com o período de inoculações dos fungos $F$. verticilioides, $S$. maydis e S. macrospora. Mas, na fase de enchimento de grãos e final de ciclo houve grande redução no volume de precipitação. Esse fato não ocorreu na segunda safra (2007/08) em que ocorreu distribuição mais uniforme das chuvas e, consequentemente, maior volume de chuvas no final do ciclo da cultura, sendo que, somente no mês de março, houve um acumulado superior aos $400 \mathrm{~mm}$ de chuvas. Essas condições são propícias para o desencadeamento das podridões de espigas (REIS; CASA, 1996). O resumo da análise de variância conjunta envolvendo os dois experimentos em sistema de plantio direto estão apresentados na Tabela 4.
Para a incidência de $S$. maydis e S. macrospora houve significância $(\mathrm{P} \leq 0,01)$ para todas as fontes de variações, exceto para as safras (2006/07 e 2007/08) (Tabela 4). A incidência e severidade dos fungos causadores do complexo de grãos ardidos, F. verticilioides, S. maydis e $S$. macrospora, foram influenciadas pelo híbrido, pela safra agrícola e pelas inoculações artificiais, em plantio direto. De maneira geral, os valores médios de severidade e incidência dos fungos Fverticilioides, S. maydis e S. macrospora foram maiores no sistema de plantio direto, quando comparados com os valores obtidos no sistema convencional.

$\mathrm{Na}$ avaliação conjunta envolvendo os dados de qualidade sanitária "blotter test", a severidade para o tratamento inoculado com o fungo $F$. verticilioides no sistema convencional foi maior na segunda safra (2007/ 08), o que não ocorreu no sistema de plantio direto, onde a maior severidade ocorreu na primeira safra (2006/07). Porém, independente do sistema de cultivo, a severidade dos tratamentos inoculados foi superior a do tratamento testemunha (sem inoculação) evidenciando o efeito das inoculações.

Os híbridos que apresentaram os menores valores de severidade na primeira safra (2006/07), para o tratamento testemunha (sem inoculação), foram o AG 6018 e 2 A 525, sendo 35,00 e 40,40, respectivamente, sendo esses híbridos pertencentes ao grupo considerado resistente aos fungos causadores de podridões de espigas (Tabela 5).

Tabela 4 - Resumo da análise de variância conjunta envolvendo as duas safras agrícolas (2006/07 e 2007/08) em sistema convencional, para as avaliações de severidade e incidência dos fungos causadores do complexo de grãos ardidos. Fazenda palheta, Luminárias, MG, 2008.

\begin{tabular}{lccc}
\hline \multirow{2}{*}{ Fonte de variação } & GL & \multicolumn{2}{c}{ QM } \\
\cline { 3 - 4 } Bloco (Safra) & 6 & 37,71 & Incidência \\
Híbridos (H) & 9 & $87,09^{* *}$ & 17,70 \\
Inoculações (I) & 1 & $5560,16^{* *}$ & $776,45^{* *}$ \\
Safra (S) & 1 & $8,10^{\mathrm{NS}}$ & $0,90^{\mathrm{NS}}$ \\
$\mathrm{H}^{*} \mathrm{I}$ & 9 & $141,35^{* *}$ & $1188,10^{* *}$ \\
$\mathrm{H}^{*} \mathrm{~S}$ & 9 & $117,11^{* *}$ & $286,67^{* *}$ \\
$\mathrm{I}^{*} \mathrm{~S}$ & 1 & $133,95^{*}$ & $343,21^{* *}$ \\
$\mathrm{H}^{*} \mathrm{I}^{*} \mathrm{~S}$ & 9 & $64,78^{* *}$ & $532,90^{* *}$ \\
Erro & 114 & 27,62 & $184,90^{* *}$ \\
\hline $\mathrm{CV}(\%)$ & & 9,95 & 39,84 \\
Média Geral & & 52,80 & 42,29 \\
\hline
\end{tabular}

${ }^{1}$ grau de liberdade para o experimento de avaliação de severidade e de incidência.

${ }^{*} \mathrm{P} \leq 0,05^{* *} \mathrm{P} \leq 0,01$; ${ }^{\text {NS }}$ Não significativo.

Ciênc. agrotec., Lavras, v. 35, n. 5, p. 931-939, set./out., 2011 
Tabela 5 - Médias de severidade do fungo Fusarium verticilioides (F), frente ao tratamento testemunha (T), sem inoculação, em 10 híbridos de milho em plantio direto, nas safras agrícolas de 2006/07 e 2007/08. Fazenda Palheta, Luminárias, MG, 2008.

\begin{tabular}{ccccc}
\hline & \multicolumn{2}{c}{ SAFRA 2006/07 } & S & T \\
\hline Híbrido & $\mathrm{F}$ & $\mathrm{T}$ & $54,80 \mathrm{aB}$ & $42,20 \mathrm{aA}$ \\
\hline AG 6018 & $58,80 \mathrm{aB}$ & $35,00 \mathrm{aA}$ & $54,40 \mathrm{aB}$ & $46,60 \mathrm{bA}$ \\
AG 8021 & $58,40 \mathrm{aB}$ & $45,60 \mathrm{bA}$ & $53,40 \mathrm{aB}$ & $45,60 \mathrm{bA}$ \\
DKB 199 & $59,20 \mathrm{aA}$ & $56,40 \mathrm{cA}$ & $56,00 \mathrm{aA}$ & $50,80 \mathrm{bA}$ \\
2 A 525 & $55,40 \mathrm{aB}$ & $40,40 \mathrm{aA}$ & $55,20 \mathrm{aB}$ & $37,00 \mathrm{aA}$ \\
NB 7215 & $62,80 \mathrm{bB}$ & $49,20 \mathrm{cA}$ & $55,60 \mathrm{aA}$ & $52,60 \mathrm{bA}$ \\
DKB 350 & $52,60 \mathrm{aA}$ & $46,40 \mathrm{bA}$ & $61,20 \mathrm{bB}$ & $49,60 \mathrm{bA}$ \\
DKB 390 & $60,20 \mathrm{bB}$ & $43,00 \mathrm{bA}$ & $53,40 \mathrm{aA}$ & $50,20 \mathrm{bA}$ \\
P 30F53 & $56,60 \mathrm{aB}$ & $43,80 \mathrm{bA}$ & $66,60 \mathrm{bB}$ & $53,60 \mathrm{bA}$ \\
2 B 710 & $61,40 \mathrm{bB}$ & $51,80 \mathrm{cA}$ & $61,00 \mathrm{bB}$ & $47,80 \mathrm{bA}$ \\
NB 7210 & $68,00 \mathrm{bB}$ & $50,60 \mathrm{cA}$ & 57,16 & 47,60 \\
\hline MÉDIA & 59,34 & 46,22 &
\end{tabular}

${ }^{1}$ Médias seguidas de mesma letra minúsculas na coluna não diferem entre si pelo teste de Scott Knott, em nível de significância de 5\%; médias seguidas de mesma letra maiúscula na linha, dentro de cada safra, não diferem significativamente pelo teste F, em nível de significância de 5\%.

Ainda na primeira safra (2006/07), para o tratamento inoculado, os híbridos que apresentaram a maior severidade para o fungo $F$. verticilioides foram o NB 7210, 2 B710 e DKB 390, pertencentes ao grupo considerado susceptível aos grãos ardidos e o NB 7215 pertencente ao grupo considerado resistente, para esses materiais, a infecção foi superior a $60 \%$. Na segunda safra (2007/08), analisando a infecção natural no tratamento testemunha (sem inoculação), os híbridos que obtiveram os menores valores de severidade foram o AG6018 e NB7215, pertencentes ao grupo considerado resistente ao "complexo grãos ardidos" (Tabela 5). As maiores severidades obtidas nos tratamentos inoculados da segunda safra (2007/08) foram para os híbridos pertencentes ao grupo susceptível aos grãos ardidos, NB 7210, DKB 390 e 2B710, com severidades superiores aos $60 \%$.

Esses resultados confirmam os dados repassados pela empresas produtoras de sementes, quanto à tolerância aos fungos causadores do "complexo de grãos ardidos". Com base nos resultados obtidos nesta pesquisa, podemos inferir que os híbridos se comportaram de formas diferentes entre si, quanto a reação ao fungo $F$. verticilioides, ficando evidente a necessidade de pesquisas, que visem a elucidar os mecanismos associados a infecção das plantas.

Vale salientar ainda, que os testes de sanidade mostraram alta severidade do fungo $F$. verticilioides, tanto no tratamento testemunha, como, principalmente, no tratamento inoculado, independentemente da safra agrícola. Esses resultados são alarmantes, visto que, o fungo pode vir a ocasionar perdas qualitativas, em razão da produção de compostos toxinogênicos, podendo causar sérios prejuízos, se utilizado para a alimentação de animais e seres humanos (PINTO, 2001).

Para os valores de incidência de podridão branca, causada pelos fungos $S$. maydis e $S$. macrospora, a avaliação individual e conjunta evidenciou o efeito das inoculações frente ao tratamento testemunha (sem inoculação), pois somente no tratamento inoculado com $S$. maydis e S. macrospora, ocorreu o aparecimento dos sintomas nos grãos avaliados pelo "blotter test", o mesmo não ocorrendo nos tratamentos inoculados com o fungo F. verticilioides e no tratamento testemunha (sem inoculação). Na avaliação da primeira safra (2006/07), para a incidência de $S$. maydis os híbridos DKB 390 e 2 B 710, obtiveram os maiores valores, 36,0 e $30,0 \%$, respectivamente (Tabela 6). Esses valores foram bastante expressivos, pois estiveram acima dos valores considerados suficientes para identificar resistência a Stenocarpella spp. entre híbridos de milho, que é de 17\%. Esses genótipos estavam enquadrados no grupo de híbridos considerados susceptíveis aos fungos causadores de grãos ardidos em milho, evidenciando a correta recomendação por parte das empresas produtoras de sementes. 
Tabela 6 - Médias de incidência de Stenocarpella maydis (MY) e Stenocarpella macrospora (MA) em 10 híbridos de milho em plantio direto, nas safras agrícolas de 2006/07 e 2007/08. Fazenda Palheta, Luminárias, MG, 2008.

\begin{tabular}{crrrr}
\hline \multicolumn{3}{c}{ MY } & \multicolumn{2}{c}{ MA } \\
\hline Híbrido & $2006 / 07$ & $2007 / 08$ & $2006 / 07$ & $9,00 \mathrm{aA}$ \\
\hline AG 6018 & $10,00 \mathrm{aA}$ & $9,00 \mathrm{aA}$ & $10,00 \mathrm{aA}$ & $6,00 \mathrm{aA}$ \\
AG 8021 & $8,00 \mathrm{aA}$ & $11,00 \mathrm{aA}$ & $11,00 \mathrm{aA}$ & $8,00 \mathrm{aA}$ \\
DKB 199 & $9,00 \mathrm{aA}$ & $8,00 \mathrm{aA}$ & $8,00 \mathrm{aA}$ & $12,00 \mathrm{aA}$ \\
2 A 525 & $8,00 \mathrm{aA}$ & $6,00 \mathrm{aA}$ & $13,00 \mathrm{aA}$ & $19,00 \mathrm{aA}$ \\
NB 7215 & $6,00 \mathrm{aB}$ & $12,00 \mathrm{aA}$ & $10,00 \mathrm{aB}$ & $16,00 \mathrm{aA}$ \\
DKB 350 & $11,00 \mathrm{aA}$ & $20,00 \mathrm{bA}$ & $12,00 \mathrm{aA}$ & $28,00 \mathrm{bA}$ \\
DKB 390 & $36,00 \mathrm{bA}$ & $26,00 \mathrm{bB}$ & $11,00 \mathrm{aB}$ & $7,00 \mathrm{aA}$ \\
P 30F53 & $8,00 \mathrm{aA}$ & $11,00 \mathrm{aA}$ & $8,00 \mathrm{aA}$ & $39,00 \mathrm{cA}$ \\
2 B 710 & $30,00 \mathrm{bA}$ & $26,00 \mathrm{bA}$ & $9,00 \mathrm{aB}$ & $50,00 \mathrm{dA}$ \\
NB 7210 & $15,00 \mathrm{aB}$ & $25,00 \mathrm{bA}$ & $11,00 \mathrm{aB}$ & 19,40 \\
\hline MÉDIA & 14,10 & 15,40 & 10,30 & \\
\hline
\end{tabular}

${ }^{1}$ Médias seguidas de mesma letra distintas minúsculas na coluna diferem entre si pelo teste de Scott Knott, em nível de significância de 5\%; médias seguidas de mesma letra distintas maiúscula na linha, dentro de cada tratamento, não diferem significativamente pelo teste $\mathrm{F}$, em nível de significância de $5 \%$.

Na primeira safra (2006/07), não houve diferença entre os híbridos inoculados com o fungo $S$. macrospora. Vale salientar que, na primeira safra (2006/07), as médias de incidência de $S$. maydis foram superiores a incidência de $S$. macrospora (Tabela 6). Para as avaliações de incidência de $S$. maydis, na segunda safra (2007/08), os híbridos que apresentaram maior incidência foram DKB 390, 2 B 710, NB 7210 e DKB 350, com as respectivas porcentagens médias de 26,0, 26,0, 25,0 e 20,0\%. Essas médias de incidência são bastante significativas visando a seleção de matérias resistentes à podridão branca.

Para a incidência de $S$. macrospora na segunda safra (2007/08), os híbridos que obtiveram os maiores valores foram NB 7210, 2 B 710 e DKB 390, com 50,0, 39,0e $28,0 \%$, respectivamente. Vale lembra que, na primeira safra (2006/07) não havia ocorrido diferença entres os híbridos para a incidência de $S$. macrospora, esse fato pode ser atribuído a maior concentração de chuvas ocorrida no final de ciclo da cultura, na segunda safra (2007/08), favorecendo a maior infecção do patógeno.

Segundo Mario e Reis (2003) e Del Rio (1990) a $S$. macrospora é, provavelmente, um competidor mais eficiente pelo sítio de infecção do milho, quando comparado a $S$. maydis. Provavelmente, em condições ideais de ambiente e com a presença das duas espécies de Stenocarpella, a incidência de $S$. macrospora seja maior que a de $S$. maydis. Essas considerações podem explicar também o fato da $S$. macrospora ter obtido média de incidência superior a $S$. maydis, na segunda safra (2007/ 08) (Tabela 6).

De maneira geral, paro o sistema de plantio direto, os maiores valores de incidência de $S$. maydis e $S$. macrospora ocorreram na segunda safra (2007/08). Esse fato, pode ser atribuído a dois fatores, sendo o primeiro o maior índice de chuvas ocorrido no final de ciclo da cultura, e o segundo, a maior disponibilidade de inóculo nos restos culturais, de onde os esporos podem ter sido liberados e transportados pelo vento até o sítio de infecção, conforme evidenciado por Mario e Reis (2003).

É importante enfatizar que os resultados desta pesquisa mostraram a importância de quantificar em laboratório, a incidência do fungo $F$. verticilioides e a severidade dos fungos S.maydis e S. macrospora nos grãos de milho colhidos, mostrando ser possível selecionar genótipos resistentes a esses fungos, causadores de podridão de grãos e espigas.

\section{CONCLUSÕES}

A avaliação pelo teste de sanidade (blotter test) evidenciou diferença entre os híbridos quanto a reação aos fungos F.verticilioides, S. maydis e S. macrospora.

Houve influencia do híbrido, da safra agrícola e do sistema de cultivo sobre a infecção dos fungos causadores de podridões de espigas, sendo que, o sistema plantio direto favorece o aumentou dos fungos responsáveis pelos grãos ardidos em milho. 
É eficiente a utilização da inoculação artificial, em campo, visando a selecionar genótipos resistentes aos fungos causadores do "complexo de grãos ardidos".

\section{REFERÊNCIASBIBLIOGRÁFICAS}

BENSCH, M.J.; VAN STADEN, J.; RIJKENBERG, J.H.F. Time and site of inoculation of maize for optimum infection of ears by Stenocarpella maydis. Journal of Phytopathology, v.136, n.4, p.265-269, 1992.

CASA, R.T.; REIS. E M.; ZAMBOLIM, L. Doenças do milho causadas por fungos do gênero Stenocarpella. Fitopatologia Brasileira, v.31, n.5, p. 427-439, set./out. 2006.

COSTA, F.M.P. Severidade de Phaeosphaeria maydis e rendimento de grãos de milho (Zea mays L.) em diferentes ambientes e doses de nitrogênio. 2001. 99p. Dissertação (Mestrado)-Escola Superior de Agricultura "Luiz de Queiroz", Piracicaba.

DEL RIO, L. Maiz muerto en Honduras provocado pôr el complejo Diplodia Y Fusarium. Manejo Integrado de Plagas, v.18, p.42-53, 1990.

EMPRESABRASILEIRADEPESQUISA AGROPECUÁRIA. Doenças na cultura do milho. Sete Lagoas: Embrapa Milho e Sorgo, 2006. Disponível em: <http://www.cnpms.embrapa.br>. Acesso em: 10 jan. 2009.

FANCELLI, A. L.; DOURADO NETO, D. Produçãode milho. Guaíba: Agropecuária, 2000.360p.

FERREIRA, D.F. SISVAR Sistemas de análises de variância para dados balanceados: programa de análises estatísticas e planejamento de experimentos. Versão 4.3. Lavras: UFLA/DEX, 2002.
FLETT, B.C.; McLAREN, N.W. Optimum disease potential for evaluating resistance to Stenocarpella maydis ear rot corn hybrids. Plant Disease, v.78, p.587$589,1994$.

KLAPPROTH, C.J.; HAWK, A.J. Evaluation of four inoculation techniques for infecting corn ears with Stenocarpella maydis. Plant Disease, v.75, p.1057-1060, 1991.

MARIO, J.L.; REIS, E.M. Quantificação do inóculo de Diplodia macrospora e de D. maydis em restos culturais, no ar e sua relação com a infecção em grãos de milho. Fitopatologia Brasileira, v.28, p.143-147, 2003.

MARIO, J.L.; REIS, E.M. Método simples para diferenciar Diplodia macrospora de D. maydis em testes de patologia de sementes de milho. Fitopatologia Brasileira, v.26, p.670-672, 2001.

McKINNEY, R.H. Influence of soil temperature and moisture on infection of wheat seedlings by Helminthosporium sativum. Journal of Agricultural Research, v.6, p.195-218, 1923.

OLIVEIRA, E.; FERNANDES, F.T.; PINTO, N.F.J.A. Doenças do milho: identificação e controle. Sete Lagoas: Embrapa Milho e Sorgo, 2005. 84p.

PINTO, N.F.J.A. Qualidade sanitária de grãos de milho. Sete Lagoas: Embrapa Milho e Sorgo, 2001. 4p.

(Comunicado Técnico, 30).

REIS, E.M.; CASA, R.T. Manual de identificaçãoe controle de doenças de milho. Passo Fundo: Aldeia Norte, 1996. 80 p. 